\title{
A message from the new editor-in-chief
}

\author{
Yasuhiro Kodera ${ }^{1}$
}

Published online: 31 October 2019

(c) The International Gastric Cancer Association and The Japanese Gastric Cancer Association 2019

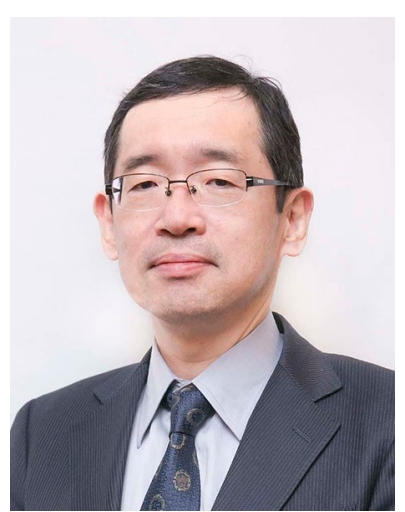

It is an immense honor for me to be appointed as the new editor-in chief of the journal Gastric Cancer effective July 2019. Gastric Cancer, founded in 1998, is an official journal of the Japanese Gastric Cancer Association (JGCA) and International Gastric Cancer Association (IGCA). As one of two editors-in-chief, I represent the JGCA and work in collaboration with Professor de Manzoni, the other editorin-chief, who represents the IGCA.

Since being invited to join the JGCA editorial team in 2000, I have been reviewing manuscripts almost throughout the history of the journal. During my career as an editorial board member, not only did I learn how the reviewers' comments are written and decisions are made, but I also enjoyed the privilege of witnessing how a highly capable leader could nurture a newly founded journal and raise its status to a height that no one even among the founding members had expected. With his vast knowledge and diligence, Dr. Takeshi Sano, the managing editor who eventually succeeded Professor Oichiro Kobori to be the second editor-in-chief on the JGCA side, read through all manuscripts submitted

Yasuhiro Kodera

ykodera@med.nagoya-u.ac.jp

1 Department of Gastroenterological Surgery (Surgery II), Nagoya University Graduate School of Medicine, Nagoya, Japan to the journal himself to handpick only manuscripts that he considered were acceptable in terms of quality and novelty. This must have been a difficult and often frustrating task, given the small number of submissions at a time when the journal did not have an impact factor, let alone the reputation it enjoys today. Consequently, the first few volumes of the journal were somewhat slim and, in addition to the original articles, contained the likes of meeting reports and special articles written by those Dr. Sano trusted. Furthermore, he scrutinized all reviewers' comments to select a handful of colleagues whom he could truly rely on, and in due time appointed them as associate editors to assist him in a dedicated team to accomplish the task of raising the status of the journal. The time, effort, and self-sacrifice that Dr. Sano and his team put into this project eventually flourished as the journal was endowed with the first impact factor of no less than 2.614 in 2009. The powerful presence of the legendary Prof. Rüdiger Siewert as an editor-in-chief on the IGCA side certainly had a great influence in motivating investigators in the west to consider submitting their works to Gastric Cancer.

The journal expanded substantially in volume and status as symbolized by the soaring impact factor during the subsequent 10 years of editorship by Prof. Yuko Kitagawa, a gentleman with immense power and resources, who succeeded Dr. Sano as the third editor-in-chief on the JGCA side. During that decade, the JGCA and IGCA also collaborated in a global project to merge the eastern and western stage classifications into the current AJCC-UICC version through analysis of big data: survival data stratified by $\mathrm{pT}$ and $\mathrm{pN}$ categories retrieved from high-volume centers throughout the world [1]. Such efforts were immensely rewarded as more in-depth discussion and comparison of data between different areas and cultures have since been made possible in international conferences and publications. Accordingly, it has now become much easier for all investigators in the world to benefit from the JGCA guidelines for the treatment of gastric cancer and annual reports from the JGCA database, all of which have been published periodically in Gastric Cancer. 
Why do these Japanese works go to print? Why does the JGCA play such an important part in this journal? Actually, Japan was in a leading position regarding early diagnosis, endoscopic resection, and surgery for gastric cancer back in 1998. Even in 2017-2018, the English version of the JGCA guidelines continued to have strong influence on the impact factor of the journal. However, I believe that in the future, a non-Japanese member of the IGCA could take over and be in full command of this journal. Who knows? The incidence of death due to gastric cancer-surprisingly, the commonest type of cancer in the United States during the early twentieth century-has now begun to decline in Japan. Nevertheless, I would like to emphasize that any future editor-in chief of this journal will invariably need to follow in the steps of Dr. Takeshi Sano to maintain the "hand-made" quality of the journal, and that will indeed be a very tough task for anybody, myself included. Gastric Cancer will continue to play its role globally as the most innovative and reliable source of information for everyone who studies and attempts to conquer gastric cancer.

\section{Reference}

1. Sano T, et al. Proposal of a new stage grouping of gastric cancer for TNM classification: International Gastric Cancer Association staging project. Gastric Cancer. 2017;20:217-25.

Publisher's Note Springer Nature remains neutral with regard to jurisdictional claims in published maps and institutional affiliations. 